\title{
Activity-Dependent Fusion Pore Expansion Regulated by a Calcineurin-Dependent Dynamin-Syndapin Pathway in Mouse Adrenal Chromaffin Cells
}

\author{
Prattana Samasilp, Shyue-An Chan, and Corey Smith \\ Department of Physiology and Biophysics, Case Western Reserve University, Cleveland, Ohio 44106-4970
}

Neuroendocrine chromaffin cells selectively secrete a variety of transmitter molecules into the circulation as a function of sympathetic activation. Activity-dependent release of transmitter species is controlled through regulation of the secretory fusion pore. Under sympathetic tone, basal synaptic excitation drives chromaffin cells to selectively secrete modest levels of catecholamine through a restricted secretory fusion pore. In contrast, elevated sympathetic activity, experienced under stress, results in fusion pore expansion to evoke maximal catecholamine release and to facilitate release of copackaged peptide transmitters. Therefore, fusion pore expansion is a key control point for the activation of the sympatho-adrenal stress response. Despite the physiological importance of this process, the molecular mechanism by which it is regulated remains unclear. Here we employ fluorescence imaging with electrophysiological and electrochemical-based approaches to investigate the role of dynamin I in the regulation of activitymediated fusion pore expansion in mouse adrenal chromaffin cells. We show that under elevated stimulation, dynamin I is dephosphorylated at Ser-774 by calcineurin. We also demonstrate that disruption of dynamin I-syndapin binding, an association regulated by calcineurin-dependent dynamin dephosphorylation, limits fusion pore expansion. Last, we show that perturbation of N-WASP function (a syndapin substrate) limits activity-mediated fusion pore expansion. Our results suggest that fusion pore expansion is regulated by a calcineurin-dependent dephosphorylation of dynamin I. Dephosphorylated dynamin I acts via a syndapin/N-WASP signaling cascade to mediate pore expansion.

\section{Introduction}

Adrenal chromaffin cells function as a major output of the sympathetic nervous system. Sympathetic excitation activates chromaffin cells to release catecholamines and peptide transmitters into the circulation, affecting a broad spectrum of functions including blood pressure, cardiac output, and blood glucose as well as afferent sensory activity (Vollmer et al., 1997; Habib et al., 2001). Improper transmitter release from the adrenal can lead to complex disease states including hypertension, diabetes, and cardiomyopathy (Pérez-Alvarez et al., 2010). Catecholamines and peptide transmitters are copacked in the same secretory granules (Winkler and Westhead, 1980; Crivellato et al., 2008); however, they are differentially secreted in an activity-dependent manner. Under basal sympathetic activity, chromaffin vesicles fuse with the plasma membrane and form a restricted fusion pore (Fulop and Smith, 2006). A highly soluble fraction of granule catechol-

Received March 16, 2012; revised June 4, 2012; accepted June 15, 2012.

Author contributions: P.S., S.-A.C., and C.S. designed research; P.S. and S.-A.C. performed research; P.S. and S.-A.C. contributed unpublished reagents/analytic tools; P.S. and S.-A.C. analyzed data; P.S. and C.S. wrote the paper.

This work was supported by a scholarship from the Royal Thai Government to P.S. and a grant from the National Institutes of Health to C.S. (GM102191). We thank Dr. Rajesh Ramachandran for helpful discussions in the design of this study.

Correspondence should be addressed to Dr. Corey Smith Department of Physiology and Biophysics, 2109 Adelbert Road, Case Western Reserve University, Cleveland, OH 44106-4970. E-mail: Corey.Smith@case.edu.

DOI:10.1523/JNEUROSCI.1299-12.2012

Copyright $\odot 2012$ the authors $\quad 0270-6474 / 12 / 3210438-10 \$ 15.00 / 0$ amine is released through the pore while the poorly soluble peptide transmitters, sequestered in the granule core, are left inside the granule lumen (Fulop et al., 2005). This transient mode of exocytosis is referred to as "kiss-and-run" fusion (Rahamimoff and Fernandez, 1997; Lindau and Alvarez de Toledo, 2003; Ryan, 2003). In contrast, after the initial formation of the fusion pore, elevated stimulation drives fusion pore expansion, maximizing catecholamine secretion and facilitating peptide transmitter release from the granule lumen (Perrais et al., 2004; Fulop et al., 2005). Thus, subsequent to initial pore formation, activitymediated pore expansion is a key step in the regulation of catecholamine quantal size as well as peptide transmitter release from chromaffin cells. However, the molecular mechanism and regulation of pore expansion remain poorly understood.

Dynamin, a large GTPase, is well recognized as effecting membrane scission during endocytosis (Damke et al., 1994). A novel role for dynamin in regulating secretion-associated behavior has recently become appreciated. Functional perturbation, through mutation or pharmacologic inhibition, alters catecholamine quantal size (Graham et al., 2002; Chen et al., 2005; González-Jamett et al., 2010) and fusion pore expansion (Fulop et al., 2008; Anantharam et al., 2011). The molecular mechanism by which dynamin regulates fusion pore dynamics and transmitter secretion remains less well described. Recently, dynamin has been shown to interact with syndapin in an activity-dependent manner (Anggono et al., 2006; Clayton et al., 2009). Syndapin has been proposed to play an important 
role in endocytic regulation by interconnecting dynamin to the Arp2/3 complex activator, N-WASP (Kessels and Qualmann, 2004). Moreover, dynamin-syndapin interaction requires calcineurin activity, which has been shown to regulate exocytic and endocytic mechanisms in chromaffin cells (Engisch and Nowycky, 1998; Chan and Smith, 2001). Ultimately, endocytosis and exocytosis are intimately linked processes, thus placing the dynamin-syndapin interaction as a potential activity-dependent regulator of fusion pore expansion.

Here, we show that dynamin I undergoes calcineurin-dependent dephosphorylation under elevated stimulation. We also report that calcineurin activity, dynamin I-syndapin interaction, and N-WASP activation are involved in the regulation of fusion pore expansion and granule collapse. Blocking these processes decreases catecholamine quantal size and limits fusion pore expansion specifically under high stimulation. Thus, our data support that activity-mediated dynamin-syndapin interaction is a key molecular step for sympatho-adrenal stress signaling.

\section{Materials and Methods}

All chemicals and reagents were obtained from Sigma-Aldrich or Fisher Scientific unless otherwise noted in the text.

Cell preparation. Chromaffin cells were isolated from adrenal glands of adult C57BL/6 mice (6- to 8-week-old mixed males and females; The Jackson Laboratory). Animals were deeply anesthetized by isoflurane (USP; Halocarbon Laboratories) inhalation and killed by decapitation. Anesthesia and euthanasia protocols were approved by the Institutional Animal Care and Use Committee of Case Western Reserve University, an accredited oversight body (federal animal welfare assurance \#A3145-01). Adrenal glands were immediately removed and placed into cooled dissociation solution containing (in $\mathrm{mm}$ ): $80 \mathrm{Na}$-glutamate, $55 \mathrm{NaCl}, 6 \mathrm{KCl}, 1$ $\mathrm{MgCl}_{2}, 10$ HEPES, and 10 glucose, $\mathrm{pH} 7.0$, osmolarity $290 \mathrm{mOsm}$. Glands were trimmed of excess fat, and adrenal cortex was removed from the medulla. Chromaffin cells were isolated as previously described (Fulop et al., 2005). Isolated cells were then plated on $25 \mathrm{~mm}$ diameter cover glasses and cultured in DMEM supplemented with ITS serum substitute (Mediatech) and penicillin/streptomycin $(100 \mathrm{U} / \mathrm{ml}$ each). The cells were incubated at $35^{\circ} \mathrm{C}$ in $10 \% \mathrm{CO}_{2}$. The experiments were performed at room temperature $\left(\sim 25^{\circ} \mathrm{C}\right)$ up to $3 \mathrm{~d}$ after cell preparation.

Fluorescence imaging. Fluorescence images were acquired on an Olympus IX-81 inverted microscope with a $40 \times$ objective $(\mathrm{NA}=$ 1.15). Excitation light was provided by a TILL Polychrometer IV (TILL Photonics) under control of SlideBook image acquisition software (SlideBook 4.1; Intelligent Imaging). Images were captured by a cooled charge-coupled device camera (Retiga EXi; QImaging) at a set exposure time and camera gain consistent throughout a dataset to allow for comparison of signal magnitude between cells and to minimize photobleach during the illumination.

Immunocytochemical staining. Cells were bathed in normal $\mathrm{K}^{+}$Ringer's solution (external potassium concentration $\left(\left[\mathrm{K}^{+}\right]_{\mathrm{o}}\right)=2.8 \mathrm{mM}$ ) or stimulated with low $\mathrm{K}^{+}$- or high $\mathrm{K}^{+}$-containing Ringer's solution for 5 $\min$. These low and high potassium solutions have been shown to quantitatively mimic stimulation intensity (per FURA-measured $\mathrm{Ca}^{2+}$ influx) and secretion kinetics to cells stimulated with native action potential equivalent (APe) waveforms at 0.5 and $15 \mathrm{~Hz}$, respectively (Fulop and Smith, 2007; Doreian et al., 2009). For low and high potassium solutions, we altered the standard electrophysiology Ringer's solution (see below) in the following manner. Extracellular $\mathrm{KCl}$ was increased to either $8 \mathrm{~mm}$ or $30 \mathrm{~mm}$, respectively, and $\mathrm{NaCl}$ was reduced to maintain osmolarity. After stimulation, cells were immediately fixed in PBS containing 4\% paraformaldehyde for $30 \mathrm{~min}$ and then washed for at least 5 min in normal PBS. Next, cells were permeabilized with PBS containing $0.15 \%$ Triton X-100 for $30 \mathrm{~min}$, washed again with PBS for $5 \mathrm{~min}$, and then blocked with PBS containing 4\% normal donkey serum for $30 \mathrm{~min}$. After blocking, cells were incubated for $2 \mathrm{~h}$ in PBS containing a primary antibody against phospho-dynamin I Ser-774 (1:500 dilution; Invitrogen), and then washed multiple times with PBS. To visualize phospho- dynamin I, cells were incubated in a secondary antibody tagged with Alexa Fluor 488 (Invitrogen), and then imaged as described above.

Electrophysiological recordings. For electrophysiological measurement, patch pipettes of $\sim 4-5 \mathrm{M} \Omega$ resistance were pulled from borosilicate glass, partially coated with molten dental wax (Electron Microscopy Sciences), and lightly fire polished. To guard against washout of exocytic and endocytic activity (Burgoyne, 1995; Smith and Neher, 1997; Engisch and Nowycky, 1998), all recordings were performed in perforated-patch configuration as previously described (Chan and Smith, 2001). The perforated-patch pipette solution contained (in mM): 135 Cs-glutamate, 10 HEPES- $\mathrm{H}, 9.5 \mathrm{NaCl}, 0.5 \mathrm{TEA}-\mathrm{Cl}$, and 0.53 amphotericin $\mathrm{B}, \mathrm{pH} 7.2$, osmolarity $320 \mathrm{mOsm}$. Amphotericin B was freshly prepared as a $100 \mathrm{X}$ stock solution in dimethylsulfoxide and diluted into the standard internal solution. During the recordings, cells were constantly superfused at a rate of $\sim 1 \mathrm{ml} / \mathrm{min}$ with a Ringer's solution of the following composition (in $\mathrm{mm}$ ): $150 \mathrm{NaCl}, 10 \mathrm{HEPES}-\mathrm{H}, 10$ glucose, $2.8 \mathrm{CaCl}_{2}, 2.8 \mathrm{KCl}$, and 2 $\mathrm{MgCl}_{2}$. The $\mathrm{pH}$ was set to 7.2 by $\mathrm{NaOH}$ and solution osmolarity was 320 mOsm. Patched cells were allowed to perforate to $<30 \mathrm{M} \Omega$ series resistance before recording. Cells with leak currents greater than $-30 \mathrm{pA}$ were excluded from analysis. Voltage-clamp records were obtained with an EPC-9 amplifier (HEKA Elektronik) controlled by Pulse software (version 8.80; HEKA Elektronik). Cells were stimulated with APe at either 0.5 or $15 \mathrm{~Hz}$ as previously described (Chan and Smith, 2001).

Electrochemical recordings. Amperometric recordings were performed as described previously (Fulop et al., 2005). Briefly, commercial $5 \mu \mathrm{m}$ diameter carbon fiber electrodes (ALA Scientific Instruments) were used to detect catecholamine release from chromaffin cells. Carbon fibers were cut daily. Fibers were lowered into the bath and the potential was clamped at $+650 \mathrm{mV}$. The fiber tip was placed close to the cell membrane to minimize the diffusion distance of catecholamine from the cell membrane. The background current of the fiber electrode was allowed to relax to a steady value before recording. The fiber was recut or replaced if the resting current was unstable or $>5 \mathrm{pA}$. Amperometric current was recorded by a dedicated amplifier (VA-10 with 1 G $\Omega$ head stage; ALA Scientific Instruments). The head stages of the VA-10 and EPC-9 amplifiers shared a common $\mathrm{AgCl}$ bath ground. A $10 \Omega$ resistor was added into the ground wire of the VA-10 to minimize the cross talk between two amplifiers. The amperometric signal was passed through an analog $1 \mathrm{kHz}$ Bessel filter and sampled at $20 \mathrm{kHz}$ through an Axon Digidata 1322A (Molecular Devices) into WinEDR software (version 2.8.9; John Dempster, University of Strathclyde).

Peptide treatment. The 11R-CaN-AID and 11R-CaN-CON peptides were synthesized by GenScript USA after previously published sequences (11RCaN-AID: GGGRMAPPRRDAMPSDA and 11R-CaN-CON: GGGRMRDR PAPAMDPSA) (Terada et al., 2003). The peptides are made cell permeant by incorporation of a poly-arginine (11R) protein transduction domain on their $\mathrm{N}$ terminus. The DynI ${ }_{769-784} \mathrm{AA}$ and $\mathrm{DynI}_{769-784}$ EE peptides were synthesized by the Molecular Biotechnology Core at the Cleveland Clinic Learner Research Institute (Cleveland, $\mathrm{OH}$ ) after previously published sequences with a penetratin tag on the $\mathrm{C}$ terminus to be made cell permeant $\left(\right.$ DynI $_{769-784}$ AA: PAGRRAPTSAPTPQRR and DynI $_{769-784}$ EE: PAGRREPTSEPTPQRR) (Anggono et al., 2006). To determine transduction efficacy, all peptides were also synthesized separately with a fluorescein tag on the $\mathrm{N}$ terminus to provide an initial fluorescence-based report of cell incorporation. Isolated chromaffin cells were acutely treated with $5 \mu \mathrm{M}$ final concentration for $5 \mathrm{~min}$ for 11R-CaN-AID and $11 \mathrm{R}-\mathrm{CaN}-\mathrm{CON}$ peptides, and $25 \mu \mathrm{m}$ final concentration for $30 \mathrm{~min}$ for DynI $_{769-784} \mathrm{AA}$ and $\mathrm{DynI}_{769-784}$ EE peptides before performing experiments. All peptides were directly added into culture medium and incubated at $35^{\circ} \mathrm{C}, 10 \% \mathrm{CO}_{2}$.

Pharmacological agents. Cells indicated as treated with N-WASP inhibitor were treated with $10 \mu \mathrm{M}$ wiskostatin (Calbiochem) $5 \mathrm{~min}$ before recording. Wiskostatin was also present during the electrophysiological recording due to its reversible effect. We found that the wiskostatin treatment decreased evoked calcium influx. Since calcium is a key regulator of the exocytic process, we supplemented extracellular calcium from 2.8 to $5 \mathrm{~mm}$ to increase influx. The extracellular calcium supplement elevated evoked calcium influx in wiskostatin-treated cells to levels statistically equal to control cells (peak calcium current $[$ mean \pm SEM] $)$ : control $=$ 
A

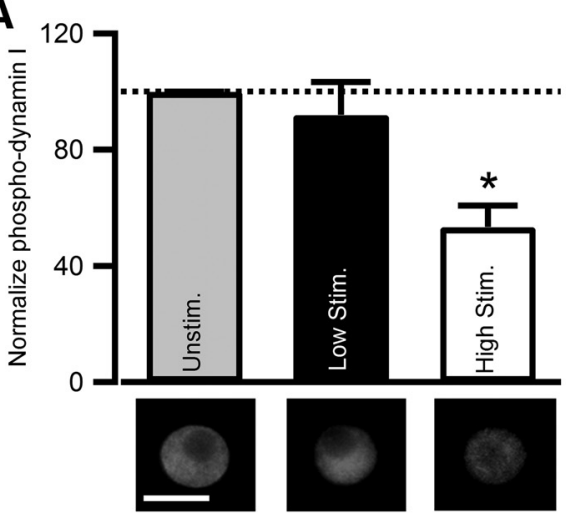

B

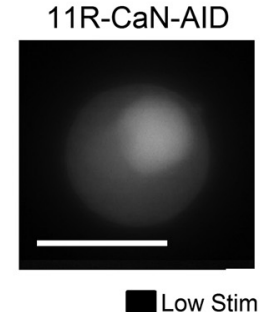

C
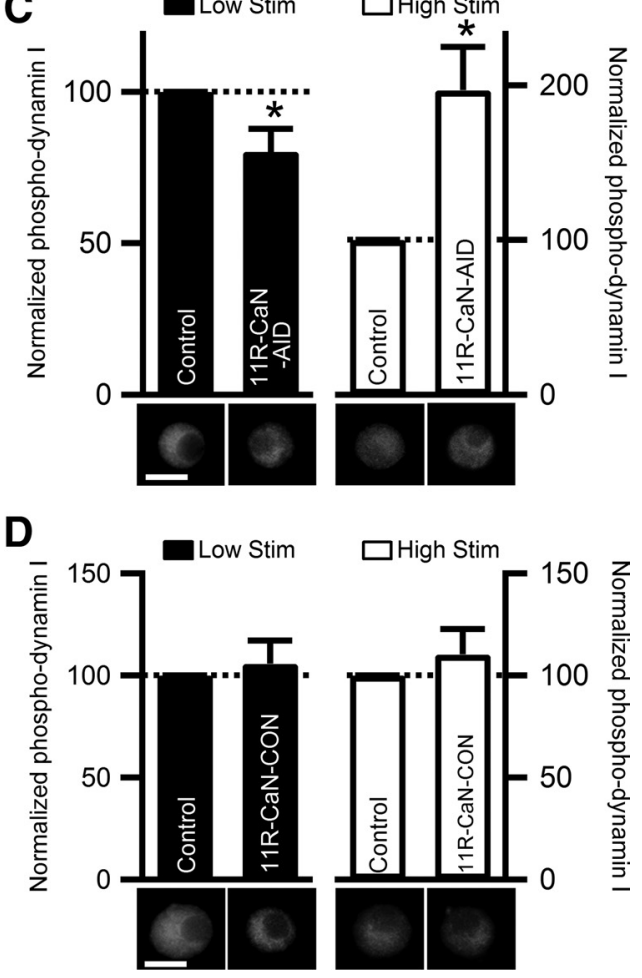

Figure 1. Calcineurin regulates activity-dependent dephosphorylation of dynamin I Ser774. $\boldsymbol{A}$, Chromaffin cells were bathed in normal HEPES-buffered Ringer's (Unstim $=2.8 \mathrm{~mm}$ $\mathrm{K}^{+}$) or stimulated with low or high potassium containing Ringer's (Low Stim. $=8 \mathrm{~mm} \mathrm{~K}^{+}$and High Stim. $=30 \mathrm{~mm} \mathrm{~K}^{+}$, respectively). Cells were then incubated with a phospho-specific Ser-774 dynamin I antibody and visualized by an Alexa Fluor 488-conjugated secondary antibody. Cellular fluorescence intensity values for each condition were normalized to unstimulated controls and are presented. Data were pooled from three experiments with each experiment consisting of at least 13 cells for each condition. $\boldsymbol{B}$, Peptide delivery was confirmed by a fluorescein-tagged peptide. Chromaffin cells were treated with fluorescein-tagged calcineurin auto-inhibitory peptide (11R-CaN-AID; left) or scrambled peptide (11R-CaN-CON; right). C, Cells were treated with 11R-CaN-AID before stimulation with low or high $\mathrm{K}^{+}$solution. Phosphodynamin I (Ser-774) immunoreactivity was quantified and normalized to untreated cells for each stimulation condition. Pooled data for each condition were from four experiments with at least 14 cells each. D, Cells were treated with 11R-CaN-CON and stimulated with low or high $\mathrm{K}^{+}$ solution. Quantified phospho-Ser-774 dynamin I immunoreactivity was again normalized to the untreated control condition. Data for each condition were pooled from three
$462.98 \pm 59.61 \mathrm{pA}(n=23$ cells $)$ and wiskostatin $+\mathrm{Ca}^{2+}=686.20 \pm$ $185.09 \mathrm{pA}$ ( $n=6$ cells $)$ for $0.5 \mathrm{~Hz}$ stimulation. Control $=192.69 \pm 13.12$ $\mathrm{pA}(n=23$ cells $)$ and wiskostatin $+\mathrm{Ca}^{2+}=160.05 \pm 21.13 \mathrm{pA}(n=8$ cells) for $15 \mathrm{~Hz}$ stimulation.

Data analysis. Amperometric records were analyzed on a single-spike basis in IGOR Pro (WaveMetrics) with a modified peak detection routine based on the "Spike" macro initially described by the Borges group (Gomez et al., 2002). Nonparametric Mann-Whitney statistical analysis of median values was performed using the MiniTab software package (version 15; MiniTab, State College, PA). Statistical significance for MannWhitney analysis was tested at $99.99 \%(p<0.001)$ confidence level with a relevance barrier of $33 \%$. Fluorescence images were analyzed using a custom-written macro in IGOR Pro. Statistical significance for mean analysis was determined by Student's $t$ test at 95\% $(p<0.05)$ confidence level.

\section{Results}

Previous studies from the Robinson and Cousin groups (Anggono et al., 2006; Clayton et al., 2009) showed that dynamin undergoes activity-dependent dephosphorylation at specific serine residues within its proline-rich domain (PRD). This dephosphorylation facilitates the binding of syndapin (synaptic dynamin-associated proteins) (Clayton et al., 2009). Dynamin-syndapin interaction has been shown to regulate the endocytic process in isolated neuronal cells (Kessels and Qualmann, 2004). In neuroendocrine chromaffin cells, dynamin I exhibits multiple roles in regulating exocytic and endocytic processes, including regulating fusion pore dynamics and catecholamine release (Elhamdani et al., 2001; Graham et al., 2002; Fulop et al., 2008; Anantharam et al., 2011). Thus, we wanted to determine whether the dynamin/syndapin regulation of endocytosis and the dynamin-dependent regulation of catecholamine quantal size were mechanistically related.

Calcineurin dephosphorylates dynamin I at serine-774 under elevated stimulation

We performed immunocytochemistry in isolated chromaffin cells to measure the activity-dependent phosphorylation status of dynamin I. Chromaffin cells were stimulated with either low $\left(\left[\mathrm{K}^{+}\right]_{\mathrm{o}}=8 \mathrm{mM}\right)$ or high $\left(\left[\mathrm{K}^{+}\right]_{\mathrm{o}}=30 \mathrm{~mm}\right)$ potassium-containing Ringer's solutions to mimic low and high stimulation levels (see Materials and Methods). After stimulation, cells were immediately fixed and permeabilized for immunofluorescence labeling. Cells were incubated with an antibody raised against phosphodynamin I Ser-774, a residue regulating syndapin binding (Anggono et al., 2006), and visualized with an Alexa Fluor 488-labeled secondary antibody. Cellular fluorescence intensity was quantified for each condition and normalized to an unstimulated control group. Category plots in Figure $1 \mathrm{~A}$ provide phosphodynamin I immunoreactivity as well as a representative image for each stimulation condition. Phospho-Ser-774 dynamin I immunoreactivity under low potassium stimulation was not significantly different from the unstimulated control. However, under high potassium stimulation, dynamin I Ser-774 phosphorylation was significantly lower than in the unstimulated control group (Fig. 1A). These data demonstrate a potassium-induced activitydependent dephosphorylation of dynamin I at Ser-774 in chromaffin cells.

\section{$\leftarrow$}

experiments of at least 7 cells each. Data are presented in mean \pm SEM. Statistical significance was determined by Student's $t$ test. An asterisk in each category indicates statistical significance with respect to untreated or unstimulated control $(p<0.05)$. Representative images for each condition provided below each category. Scale bars, $15 \mu \mathrm{m}$. 
It has been shown in neuronal systems that dynamin is a major substrate of the serine-threonine protein phosphatase, calcineurin (Liu et al., 1994). Moreover, calcineurin activity is positively regulated by calcium-calmodulin, and thus is expected to exhibit an activity dependence. We initiated experiments to test whether calcineurin is responsible for activity-dependent dynamin I dephosphorylation in chromaffin cells. We used a previously characterized calcineurin auto-inhibitory peptide (11R-CaN-AID) to block calcineurin phosphatase activity (Terada et al., 2003). The inactive scrambled peptide (11R-CaN-CON) served as a negative control. Both peptides contain a poly-arginine-based protein transduction domain to deliver the peptide into cells as previously published (Terada et al., 2003). We also synthesized the $11 \mathrm{R}-\mathrm{CaN}-\mathrm{AID}$ and $11 \mathrm{R}-\mathrm{CaN}-\mathrm{CON}$ peptides with a fluorescein tag on the $\mathrm{N}$ terminus to positively determine transduction efficacy and establish the treatment protocol. Isolated chromaffin cells were acutely treated with either $5 \mu \mathrm{M} 11 \mathrm{R}-\mathrm{CaN}-\mathrm{AID}$ or $11 \mathrm{R}-\mathrm{CaN}-\mathrm{CON}$ for $5 \mathrm{~min}$ or left untreated as control. The chromaffin cells showed strong peptide transduction, reported by fluorescence internalization, after $5 \mathrm{~min}$ incubation in $5 \mu \mathrm{M}$ peptide (Fig. $1 \mathrm{~B}$ ). After treatment with unlabeled peptides, cells were stimulated with low or high potassium Ringer's, immune-labeled with dynamin I phospho-Ser-774 primary antibody, and visualized with Alexa Fluor 488-labeled secondary antibody. Immunoreactivity of each stimulation condition was measured and normalized to untreated control cells. Sample images and category plots for each experimental condition are presented in Figure 1, $C$ and D. Calcineurin inhibition by treatment with the 11R-CaN-AID peptide blocked dephosphorylation of Ser-774 dynamin I normally observed under high potassium stimulation (Fig. $1 C$ ). We also observed a small decrease in dynamin phosphorylation under low potassium stimulation. This point will be addressed below. As expected, no change of Ser-774 dynamin I phosphorylation was observed in 11R-CaN-CON peptide-treated cells under any stimulation condition (Fig. 1D). Together, these data suggest that in chromaffin cells, as shown in synaptosomes (Anggono et al., 2006), calcineurin activity is required for activity-dependent dephosphorylation of dynamin I at Ser-774, thus activating the syndapin-binding PRD domain.

\section{Calcineurin activity is required for an activity-dependent increase in catecholamine quantal size}

Electrochemical carbon fiber amperometry is a highly sensitive approach that is able to detect catecholamine secretion at the single granule level (Wightman et al., 1991; Chow et al., 1992). We used amperometry with electrophysiological voltage-clamp methods to manipulate stimulation and directly measure catecholamine released from the chromaffin cells. In this set of experiments, catecholamine quantal size was measured from cells stimulated with trains of APe voltage waveforms (Chan and Smith, 2001) delivered at $0.5 \mathrm{~Hz}$ or $15 \mathrm{~Hz}$ to approximate electrical activity of chromaffin cells under basal sympathetic tone or under acute stress, respectively (Brandt et al., 1976; Chan and Smith, 2001). Representative amperometric traces recorded from single chromaffin cells stimulated with APe trains at either $0.5 \mathrm{~Hz}$ or $15 \mathrm{~Hz}$ are shown in Figure $2 \mathrm{~A}$ and demonstrate a shift toward larger amperometric spikes with increased stimulus intensity. Each spike represents the release of catecholamine from a single vesicle (Leszczyszyn et al., 1990). We quantified quantal size as spike charge (picocoulomb) for each condition by integrating the area under each amperometric event (Fig. $2 \mathrm{Bi}$, gray area, inset). Catecholamine quantal size has been shown to increase related to expansion of the fusion pore and facilitation of granule emptying
A $0.5 \mathrm{~Hz}$
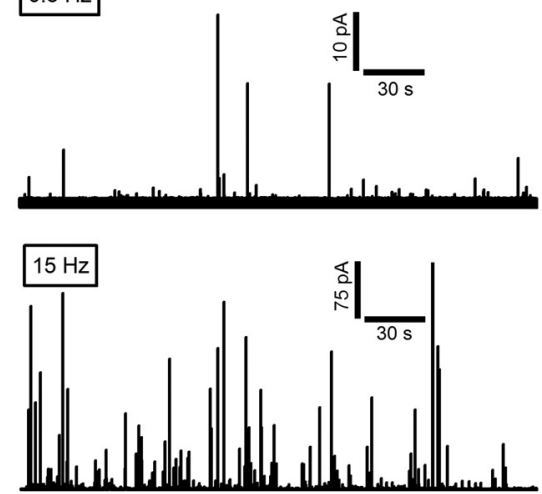

B

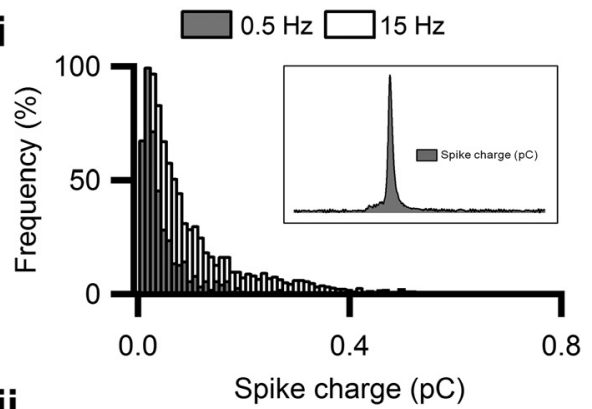

ii

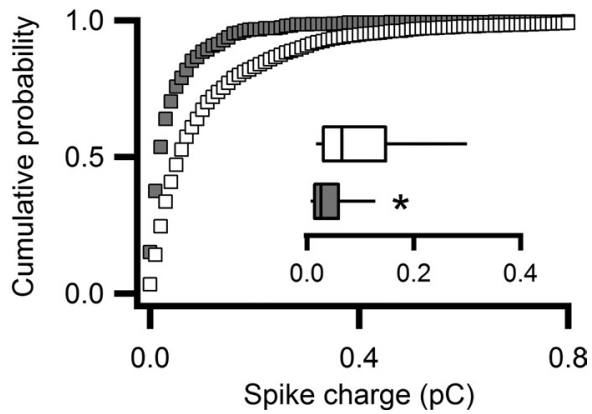

Figure 2. Amperometric analysis of catecholamine secretion under 0.5 and $15 \mathrm{~Hz}$ stimulation. Single adrenal chromaffin cells were held in perforated-patch voltage-clamp and stimulated with trains of APe delivered at $0.5 \mathrm{~Hz}$ or $15 \mathrm{~Hz}$. Quantal catecholamine release was detected by electrochemical amperometry. $\boldsymbol{A}$, Representative traces recorded from $0.5 \mathrm{~Hz}-$ stimulated (top) and $15 \mathrm{~Hz}$ (bottom)-stimulated cells are provided (note the difference in vertical scale). Bi, The frequency distribution of spike charge for each condition exhibits a skewed distribution. The inset shows an example of a single spike with the integral area grayed. Bii, Pooled cumulative probability plots of spike charge are presented. The inset shows each dataset in box-and-whisker plot format. Parameters for the box-and-whisker plots are as follows: 10th percentile, 1st quartile, median, 3rd quartile, and 90th percentile observation. Statistical significance was determined by nonparametric Mann-Whitney median analysis as described in Materials and Methods. An asterisk indicates a statistically significant difference at $p<0.001$ with a relevance barrier of $33 \% . n$ (spikes): 573 from 23 cells for $0.5 \mathrm{~Hz}$ and 3880 from 23 cells for $15 \mathrm{~Hz}$.

(Graham et al., 2002; Barclay et al., 2004; Fulop et al., 2005; Fulop and Smith, 2006). The frequency distribution of spike charge showed that this parameter did not follow a normal distribution, but was skewed toward larger events (Fig. 2 Bi; Fulop and Smith, 2007). Thus, we quantified amperometric records and compared datasets by median rather than mean and determined statistical significance by a nonparametric Mann-Whitney test (Mosharov and Sulzer, 2005; Fulop and Smith, 2007). The dataset used to generate the cumulative probability plot is accompanied by an inset box-and-whisker plot showing data distribution and statistical analysis (Fig. 2Bii). The Mann-Whitney median test indi- 
cated that spike charge was significantly greater under $15 \mathrm{~Hz}$ stimulation than $0.5 \mathrm{~Hz}$ stimulation (Fig. 2 Bii, inset). Table 1 provides the complete set of spike charge numerical median values for each condition in this study. Many studies report amperometric data as mean \pm SEM; therefore, we also provide mean spike charge data for each condition in Table 1 for comparison to the literature. For the rest of our experiments, amperometric spike charge data will be presented in the form of cumulative probability accompanied by the median and percentile box-andwhisker plot as an inset.

Next we perturbed calcineurin activity by pretreatment with the auto-inhibitory peptide and determined its effects on catecholamine secretion. Chromaffin cells were pretreated with either 11R-CaN-AID peptide to inhibit calcineurin function or $11 \mathrm{R}-\mathrm{CaN}-\mathrm{CON}$ peptide as a negative control as in Figure 1. The cells were then voltage clamped and stimulated with APe at $15 \mathrm{~Hz}$ or $0.5 \mathrm{~Hz}$. Catecholamine secretory events were detected by carbon fiber amperometry as above. Examples of raw traces of treatment conditions are provided in Figure $3 A$ for comparison. Quantitative data of amperometric spike charge are presented in cumulative probability plots (Fig. $3 B, C$ ). Treatment with the $11 \mathrm{R}-\mathrm{CaN}$-AID peptide significantly decreased spike charge under $15 \mathrm{~Hz}$ stimulation, as indicated in median analysis (Fig. 3Bi, inset) and caused a shift in the cumulative probability curve toward the control curve measured in $0.5 \mathrm{~Hz}$ untreated cells (Fig. 3Bii, dashed line). The $11 \mathrm{R}-\mathrm{CaN}-\mathrm{CON}$ peptide, on the other hand, had no effect on spike charge at the same frequency stimulation (Fig. 3Bii; Table 1). For low stimulation condition, no change in spike charge was observed in either $11 \mathrm{R}-\mathrm{CaN}-\mathrm{AID}$ or $11 \mathrm{R}-\mathrm{CaN}-\mathrm{CON}$ peptide-treated cells when challenged with $0.5 \mathrm{~Hz}$ APe trains (Fig. 3Ci,Cii; Table 1). Together with data presented in Figure 1 , these data support that dephosphorylation of dynamin I Ser-774, and the key PRD-regulatory residue controlling syndapin binding (Anggono et al., 2006) correlates to an increased catecholamine quantal size under elevated stimulation condition.

\section{Disruption of dynamin I-syndapin interaction decreases catecholamine quantal size}

Next, we looked at the potential role of dynamin I-syndapin interaction on catecholamine secretion. We used two well-characterized peptide fragments encompassing the dynamin I PRD phosphobox, engineered with double mutations of Ser-774 and Ser-778 (Anggono et al., 2006). DynI $_{769-784}$ AA has serine to alanine substitutions at both serine sites to block phosphorylation and to act as a competitive inhibitor to native dynamin I/syndapin binding (Anggono et al., 2006; Clayton et al., 2009). Phospho-mimetic DynI ${ }_{769-784} \mathrm{EE}$ contains serine to glutamate substitutions at the same sites and serves as a negative con-
Table 1. Summary of amperometric data

\begin{tabular}{|c|c|c|c|}
\hline \multirow[b]{2}{*}{ Condition } & \multicolumn{2}{|l|}{ Spike charge (pC) } & \multirow[b]{2}{*}{ Preparation } \\
\hline & Median (spikes) & Mean \pm SEM (cells) & \\
\hline \multicolumn{4}{|l|}{$0.5 \mathrm{~Hz}$} \\
\hline Control & $0.0265(573)$ & $0.0581 \pm 0.0076(23)$ & 16 \\
\hline 11R-CaN-AID & $0.0241(291)$ & $0.0398 \pm 0.0048$ & 4 \\
\hline 11R-CaN-CON & $0.0296(327)$ & $0.0387 \pm 0.0077(10)$ & 4 \\
\hline Dynl $_{769-784} A A$ & $0.0349(323)$ & $0.0496 \pm 0.0072(12)$ & 3 \\
\hline Dynl $_{769-784} \mathrm{EE}$ & $0.0347(324)$ & $0.0554 \pm 0.0090(12)$ & 4 \\
\hline Wisk $+\mathrm{Ca}^{2+}$ & $0.0211(184)$ & $0.0504 \pm 0.0161(6)$ & 5 \\
\hline \multicolumn{4}{|l|}{$15 \mathrm{~Hz}$} \\
\hline Control & $0.0653(3880)$ & $0.1193 \pm 0.0088(23)$ & 19 \\
\hline 11R-CaN-AID & $0.0279(1171)^{*}$ & $0.0475 \pm 0.0062(10)^{*}$ & 6 \\
\hline 11R-CaN-CON & $0.0631(3851)$ & $0.1209 \pm 0.0113(10)$ & 4 \\
\hline Dynl $_{769-784} A A$ & $0.0426(1640)^{*}$ & $0.0767 \pm 0.0111(13)^{*}$ & 5 \\
\hline Dynl $_{769-784} \mathrm{EE}$ & $0.0603(2125)$ & $0.1130 \pm 0.0117(14)$ & 7 \\
\hline Wisk $+\mathrm{Ca}^{2+}$ & $0.0126(471)^{*}$ & $0.0203 \pm 0.0030(8)^{*}$ & 3 \\
\hline
\end{tabular}

Spike charge for each experimental category. Spike charge values are presented as both median of pooled spike and mean \pm SEM of pooled cell. Each experimental condition was statistically compared to control in the same frequency stimulation $(0.5 \mathrm{~Hz}$ or $15 \mathrm{~Hz})$ by nonparametric Mann-Whitney median test for median analysis and Student's $t$ test for mean analysis. *Statistically significant difference $(p<0.001$ and $p<0.01$ for median and mean analysis, respectively).

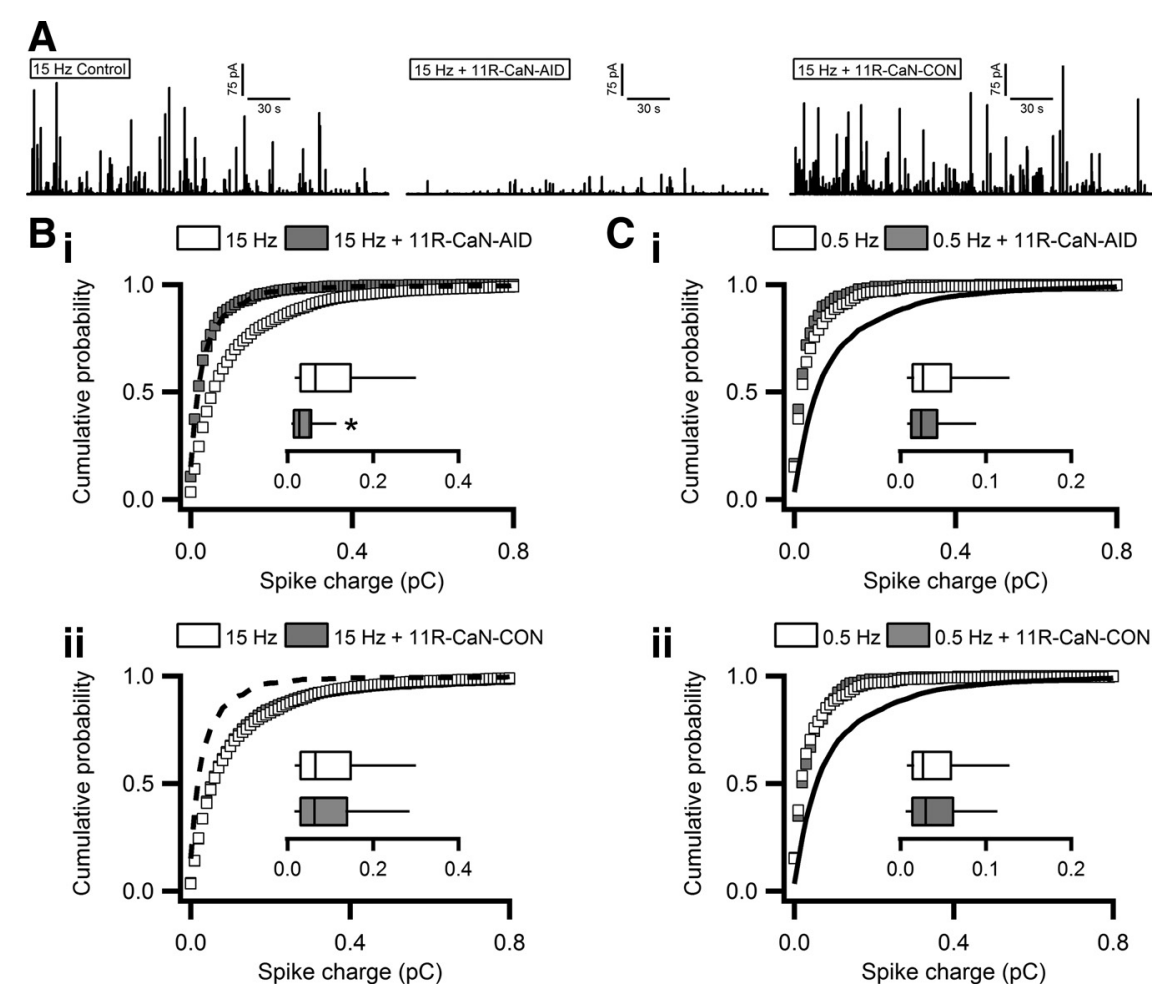

Figure 3. Calcineurin inhibition decreases spike charge specifically under $15 \mathrm{~Hz}$ stimulation. Chromaffin cells were acutely treated with the calcineurin auto-inhibitory peptide (11R-CaN-AID) or the control peptide (11R-CaN-CON) as in Figure 1. Cells were stimulated with either $15 \mathrm{~Hz}$ or $0.5 \mathrm{~Hz}$ trains of APe. Catecholamine release was measured by carbon fiber amperometry. $\boldsymbol{A}$, Examples of raw amperometric traces for untreated (left trace), 11R-CaN-AID-treated (middle trace), and 11R-CaN-CON-treated (right trace) cells stimulated at $15 \mathrm{~Hz}$ are provided. Bi, Cumulative probability plots of spike charge for control and 11R-CaN-AID conditions under $15 \mathrm{~Hz}$ stimulation are provided. The inset box-and-whisker plots show that 11R-CaN-AID decreased spike charge significantly with respect to control. Statistical significance is indicated by an asterisk as above. ( $n=3880$ spikes from 23 cells for control, and 1171 spikes from 10 cells for 11R-CaN-AID). Bii, Cumulative probability for control and 11R-CaN-CON-treated cells under $15 \mathrm{~Hz}$ stimulation are plotted. The inset box-and-whisker plot shows 11R-CaN-CON had no effect on spike charge compared with control ( $n=3880$ spikes from 23 cells and 3851 spikes from 10 cells for control and 11R-CaN-CON, respectively). The dashed line represents control data from untreated cells stimulated at $0.5 \mathrm{~Hz}$ for comparison. Ci, Cii, Cumulative probability of spike charge for 11R-CaN-AID, 11R-CaN-CON, and control $0.5 \mathrm{~Hz}$ stimulation datasets are plotted. Solid lines show control data from untreated cells stimulated with $15 \mathrm{~Hz}$ APe for comparison. Box-and-whisker plots in insets of each graph indicate that there is no statistically significant difference between peptide-treated groups (11R-CaN-AID or 11R-CaN-CON) and control group (Mann-Whitney median analysis). Sample size: 573 spikes from 23 cells for control, 291 spikes from 11 cells for 11R-CaN-AID, and 327 spikes from 10 cells for 11R-CaN-CON. 
A
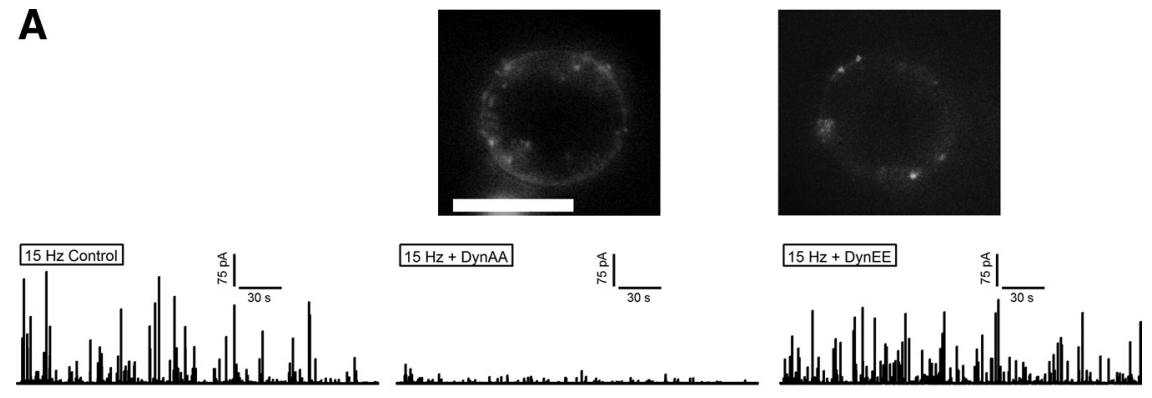

$\mathrm{B}_{\mathbf{i}}$

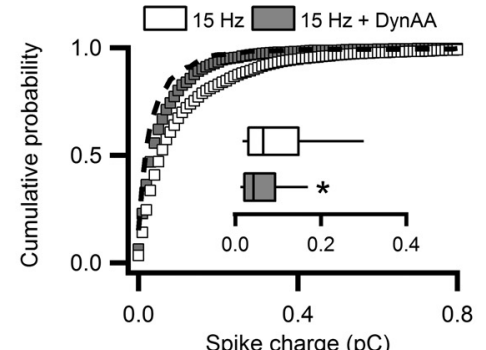

$c_{i}$
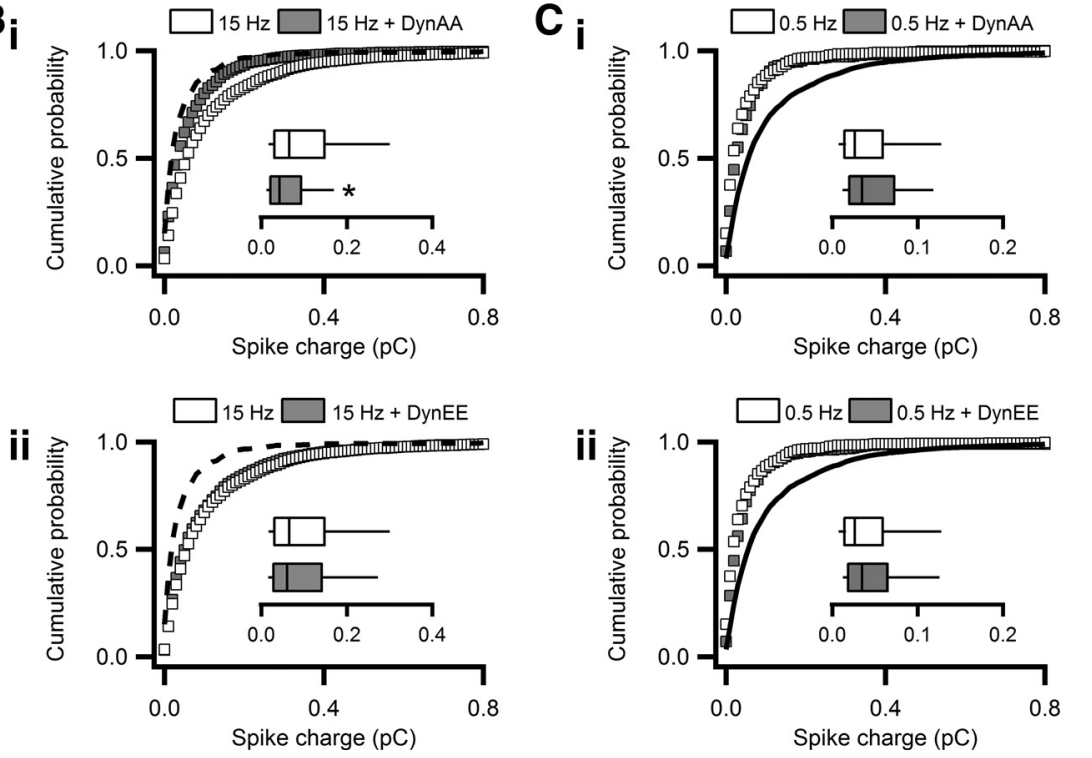

Figure 4. Perturbation of dynamin I-syndapin interaction decreases quantal size under elevated stimulation. Chromaffin cells were treated with either $25 \mu \mathrm{m} \mathrm{Dynl}_{769-784} \mathrm{AA}$ or Dynl ${ }_{769-784} \mathrm{EE}$ peptide for $30 \mathrm{~min}$. A, Raw images above corresponding raw amperometric records demonstrate peptide delivery into the cell. Scale bar, $15 \mu \mathrm{m}$. Cells were stimulated with $15 \mathrm{~Hz}$ or $0.5 \mathrm{~Hz} \mathrm{APe}$ trains. Catecholamine release was monitored for each condition for entire stimulation protocol. Examples of amperometric record-

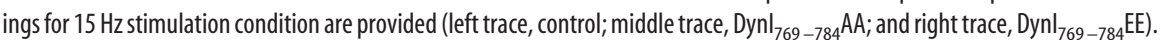
Bi, Bii, Cumulative probability plots of pooled spike charge values from each peptide-treated group (Dynl ${ }_{769-784} A_{A}$ or Dynl ${ }_{769}$ ${ }_{784} \mathrm{EE}$ ) and untreated control cells under $15 \mathrm{~Hz}$ stimulation are plotted. Dashed lines represent control data from untreated cells stimulated with $0.5 \mathrm{~Hz}$ APe trains for comparison. Dynl ${ }_{769-784} \mathrm{AA}$ treatment resulted in a significant decrease of spike charge $\left(^{*}\right)$ under high stimulation. There was no change of spike charge in Dynl ${ }_{769-784}$ EE-treated cells compared with control. $n=3880$ spikes from 23 cells for control, 1640 spikes from 13 cells for Dynl ${ }_{769-784} \mathrm{AA}$, and 2125 spikes from 14 cells for Dynl ${ }_{769-784}$ EE. Ci, Cii, Pooled spike charge values of $0.5 \mathrm{~Hz}$ stimulation condition are shown in cumulative probability plots. Solid lines provide the control dataset from untreated cells stimulated with $15 \mathrm{~Hz}$ APe trains for comparison. The inset box-and-whisker plots show no effect on quantal size for either Dynl ${ }_{769-784} \mathrm{AA}$ or Dynl ${ }_{769-784} \mathrm{EE} . n=573$ spikes from 23 cells for control, 323 spikes from 12 cells for Dynl $_{769-784} A A$, and 324 spikes from 12 cells for Dynl ${ }_{769-784} E$.

trol for the active inhibitory peptide (Anggono et al., 2006; Clayton et al., 2009). Chromaffin cells were acutely treated with either $25 \mu \mathrm{M} \mathrm{DynI}_{769-}$ 784AA or DynI ${ }_{769-784} \mathrm{EE}$ as described in Materials and Methods, and example images demonstrating peptide transduction are provided above relevant raw amperometric traces in Figure $4 \mathrm{~A}$. Cells were then held in the perforated patch voltage-clamp configuration and stimulated with trains of APe at $0.5 \mathrm{~Hz}$ or 15 $\mathrm{Hz}$. Catecholamine release was detected by amperometry as described in Figure 2. Amperometric traces for each condition are presented in Figure $4 A$. Pooled spike charge datasets of DynI $_{769-784} \mathrm{AA}$ - or DynI ${ }_{769-784}$ EE-treated cells were coplotted with untreated control stimulated with the similar frequency dataset for comparison (15 Hz: Fig. 4Bi,Bii; 0.5 Hz: Fig. 4Ci,Cii). We found the similar trend in the response of catecholamine release as described for calcineurin auto-inhibitory peptide experiments. DynI ${ }_{769-784}$ AA reduced spike charge significantly under high stimulation as shown in both the cumulative probability and the box-andwhisker plot (Fig. 4Bi). DynI ${ }_{769-784}$ EE had no effect on individual pore expansion. secretory events in both frequency stimulations (Fig. 4Bii,Cii; Table 1). These data indicate that inhibition of the interaction between dynamin I and syndapin blocks the normal activity-mediated increase in catecholamine quantal size.

In addition to spike charge, we also calculated prespike foot (PSF) current from individual amperometric spikes recorded from each condition. This parameter correlates to the initial pore opening (Chow et al., 1992; Albillos et al., 1997) and is not expected to be affected by eventual pore expansion/dissolution as the granule collapses. Consistent with this role, we found that blocking calcineurin activity and disrupting dynamin I-syndapin interaction had no effect on PSF current under either stimulation condition (data not shown).

\section{Activity-dependent exocytic transition requires $\mathrm{N}$-WASP activation}

The data presented above support a significant role for dynamin I-syndapin interaction in the regulation of activity-dependent fusion pore expansion and transition of exocytic mode. In addition to dynamin, multimeric syndapin also interacts with $\mathrm{N}$-WASP, relieving an auto-inhibition and functionally linking dynamin to N-WASP activation (Kessels and Qualmann, 2004, 2006). Therefore, we wanted to know if dynamin I/syndapin-dependent regulation proceeds through the N-WASP-dependent pathway. We used a pharmacological tool to block N-WASP activation and then measured catecholamine quantal size from chromaffin cells as above. Wiskostatin is an inhibitor of N-WASP-dependent signaling, stabilizing the auto-inhibitory conformation (Peterson et al., 2004; Deacon and Peterson, 2008). We pretreated chromaffin cells with $10 \mu \mathrm{M}$ wiskostatin for $5 \mathrm{~min}$ before and during stimulating the cells with $0.5 \mathrm{~Hz}$ or $15 \mathrm{~Hz}$ APe trains. Wiskostatin treatment decreased evoked $\mathrm{Ca}^{2+}$ influx. Therefore, we supplemented extracellular $\mathrm{Ca}^{2+}$ as described in Materials and Methods to compensate. Catecholamine release was detected by carbon fiber amperometry as above. Representative amperometric traces for control and wiskostatin treatment under high stimulation are provided in Figure 5A for comparison (note the different scale bars for each condition). Individual spike charge was analyzed for each condition as above. Pooled spike charge values measured from wiskostatin-treated cells are presented in cumulative probability plot along with their untreated control for each frequency stimulation. Inset box-and-whisker plots indicate that wiskostatin diminished spike charge significantly under $15 \mathrm{~Hz}$ stimulation, whereas it had no effect on spike charge under $0.5 \mathrm{~Hz}$ stimulation (Fig. 5Bi,Bii; Table 1). These data indicate that N-WASP activation is necessary for the regulation of activity-dependent catecholamine secretion and fusion 
A
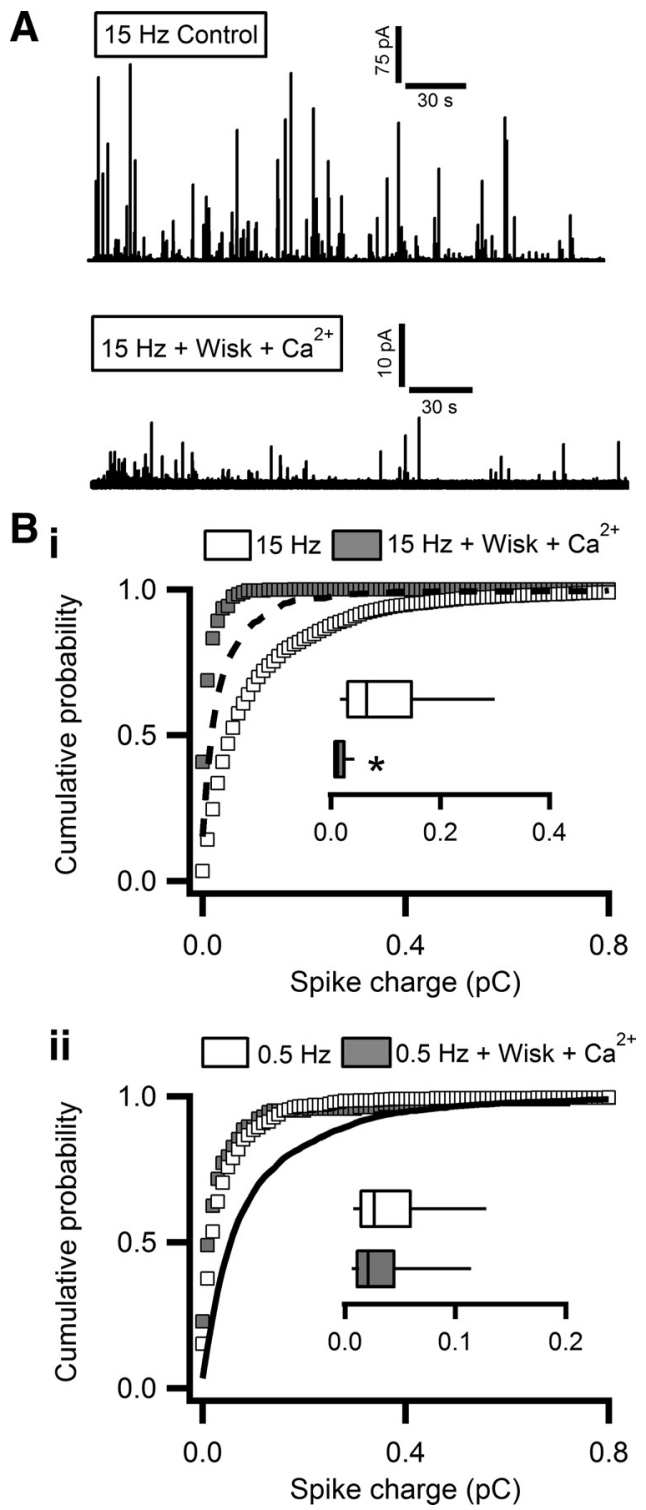

Figure 5. N-WASP activation is required for regulation of catecholamine quantal size under high stimulation. Chromaffin cells were pretreated with $10 \mu \mathrm{m}$ wiskostatin for 5 min to stabilize $\mathrm{N}$-WASP into its auto-inhibitory conformation. Cells were then stimulated with either $15 \mathrm{~Hz}$ or $0.5 \mathrm{~Hz}$ APe trains. The cells were continuously perfused with Ringer's solution containing $10 \mu \mathrm{m}$ wiskostatin for entire stimulation protocols. $A$, Representative amperometric traces of cells stimulated at $15 \mathrm{~Hz}$ for untreated cells (upper trace) and wiskostatin-treated cells (lower trace) are provided. $\boldsymbol{B i}$, Pooled spike charge analyzed from amperometric traces for each condition under $15 \mathrm{~Hz}$ stimulation is shown in cumulative probability plot. The dashed line shows a dataset of untreated cells stimulated with $0.5 \mathrm{~Hz}$ APe for comparison. The inset box-andwhisker plot indicates that wiskostatin significantly $\left({ }^{*}\right.$, determined as above) diminished catecholamine quantal size compared with control under high stimulation. $n=3880$ spikes from 23 cells and 471 spikes from 8 cells for control and Wisk $+\mathrm{Ca}^{2+}$, respectively. Bii, Cumulative probability plot of pooled spike charge for untreated and wiskostatin-treated cells under $0.5 \mathrm{~Hz}$ stimulation are provided. Solid line represents a dataset of untreated cells under $15 \mathrm{~Hz}$ stimulation for comparison. Wiskostatin had no effect on spike charge at $0.5 \mathrm{~Hz}$ stimulation with respect to control as shown in box-and-whisker plot $(n=573$ spikes from 23 cells for control and 184 spikes from 6 cells for Wisk $\left.+\mathrm{Ca}^{2+}\right)$.

\section{Discussion}

A large body of accumulating evidence has established that the initial formation of the secretory fusion pore is due to a SNARE complex-mediated vesicle-cell membrane interaction (Fang et al., 2008; Ngatchou et al., 2010; Wiederhold et al., 2010). The opening of the pore is triggered by a synaptotagmin-dependent process (Wang et al., 2006; Zhang et al., 2010). After this initial formation, subsequent secondary expansion of the fusion pore has been shown to be a regulated process that plays a vital role in the postfusion regulation of transmitter release. In adrenal chromaffin cells, pore expansion has been demonstrated to determine an activity-dependent increase in catecholamine quantal size as well as determining peptide transmitter release (Elhamdani et al., 2001; Fulop et al., 2005). Recent molecular characterization has shown that dynamin plays an essential role in the regulation of fusion pore expansion (Fulop et al., 2008; Anantharam et al., 2011) and thus determines catecholamine quantal size (Graham et al., 2002; Chen et al., 2005; González-Jamett et al., 2010). In addition to dynamin, the protein phosphatase calcineurin is involved in the activitydriven change in the mode of secretory granule membrane trafficking (Engisch and Nowycky, 1998; Chan and Smith, 2001). Dynamin has been shown as a major substrate for calcineurin in the nerve terminal (Liu et al., 1994); however, a direct relationship and mechanistic contribution of both molecules in regulation of catecholamine release from neuroendocrine chromaffin cells remained to be determined. Data presented here show that calcineurin dephosphorylates dynamin I in an activity-dependent manner at stimulation levels designed to mimic electrical activity under acute stress. Blocking calcineurin activity by cell transduction with a calcineurin auto-inhibitory peptide prevents normal dynamin I dephosphorylation. Thus, calcineurin-dependent, activity-regulated dynamin I dephosphorylation at least correlates with fusion pore expansion, increased catecholamine quantal size, and facilitation of peptide transmitter release.

Calcineurin is activated via a calcium-calmodulin-dependent pathway that requires cytosolic calcium in the low micromolar range (Stewart et al., 1983; Perrino et al., 1995). Recent studies have shown that calcineurin-dynamin interaction is essential for dynamin dephosphorylation and occurs in a calcium-dependent manner (Lai et al., 1999; Xue et al., 2011). Moreover, fusion pore expansion and the associated shift in exocytic mode show a dependence on calcium influx (Elhamdani et al., 2006; Fulop and Smith, 2006) in a range matching calcineurin-activation threshold (Chan et al., 2003). We provide data that show the inhibition of calcineurin blocks the expansion of the fusion pore, thus establishing causation between calcineurin activity and pore expansion. Indeed, a small catecholamine quantal size correlates with a narrowed fusion pore (Fulop et al., 2005). These data are consistent with previous studies showing that calcineurin activity is essential for the activity-dependent transition in the exoendocytic cycle in chromaffin cells (Engisch and Nowycky, 1998; Chan and Smith, 2001) and infer the involvement of dynamin I dephosphorylation in this process. Therefore, we proposed that calcineurin represents a key point for selecting proper exocytic mode with respect to stimulus intensity by decreasing dynamin I phosphorylation in chromaffin cells.

In a seemingly unexpected result, we provide data demonstrating that calcineurin inhibition slightly decreased the phosphorylation level of dynamin I at Ser-774 even under low stimulation (Fig. 1C). This may be due to several factors. It is possible that blocking normal calcineurin activity might affect inhibition of other kinases, including C $\mathrm{dk} 5$, which together with calcineurin sets the overall phosphorylation status of dynamin (Nguyen and Bibb, 2003). Another more likely potential source for this decrease is that the mode of exocytosis, while weighted to kiss-and-run, is indeed not homogenous under low stimulation 
conditions and that even with low cytosolic calcium, some level of fusion pore expansion does occur. This would provide a limited number of pore expansion events that remain susceptible to calcineurin block even under low-frequency stimulation. In support of this possibility, although there is a high degree of significance in the activity-dependent shift in distribution, the amperometric spike charge data do exhibit overlap between low- and highfrequency stimulation. Morphologically, this behavior pattern would be expected in fusion events that are very close to calcium channels and thus experience a higher calcium concentration than the average fusion event. Indeed, previous work in primary bovine chromaffin cells has shown that while a vast majority of fusion events are not colocalized to calcium channels, a small fraction of fusion events are tightly coupled to sites of calcium influx (Klingauf and Neher, 1997), making this second scenario the likely source for the small effect of calcineurin block under low-frequency stimulation.

Dynamin-mediated effects on fusion pore behavior have been demonstrated in the literature. Dynamin GTPase activity has recently been reported to regulate fusion pore expansion. Dynamin mutants deficient in GTPase activity slow fusion pore expansion, while mutants exhibiting increased GTPase activity accelerate fusion pore widening (Anantharam et al., 2011). Moreover, interaction of dynamin with other proteins such as amphiphysin and synaptophysin also plays an important role in regulation of fusion pore dynamics and catecholamine secretion (Graham et al., 2002; Fulop et al., 2008; González-Jamett et al., 2010). Dynamin contains a pleckstrin homology domain (PHD) that binds the lipid bilayer and changes membrane topology (Bashkirov et al., 2008; Schmid and Frolov, 2011). This function of dynamin may be observed as membrane deformation during initial fusion pore formation (Anantharam et al., 2011) and in membrane collaring during the endocytic fission process (Ramachandran, 2011) via its GTPase activity. It will be interesting to examine dynamin mutations in the PHD to determine whether they too alter catecholamine secretion and fusion pore expansion. Ultimately, it is becoming more likely that chromaffin cells use multiple convergent pathways, as indicated by multiple dynamin-sensitive steps and binding partners, for precise regulation of the fusion pore during the secretory process.

The phospho-status of dynamin PRD regulates the interaction with Src homology 3-domain-containing binding partners. In this study we measured dynamin I phosphorylation at serine 774 , a regulatory residue in the PRD domain that controls access to binding partners in a phospho-dependent manner, as a function of cell stimulation. Dephosphorylation at this site results in specific recruitment of syndapin, a dynamin partner required for regulation of synaptic transmission (Anggono et al., 2006; Clayton et al., 2009). Our results reveal a critical role of phospho-dependent dynamin I-syndapin binding in exocytic mode transition. Amperometric catecholamine detection, a direct measure of quantal exocytosis, shows that dynamin I-syndapin interaction is involved in the regulation of fusion pore expansion. Disruption of dynamin I-syndapin binding by the DynI ${ }_{769-784} \mathrm{AA}$ inhibitory peptide decreased catecholamine quantal size under elevated stimulation, indicating an inhibition of fusion pore expansion. The inhibitory peptide used in these experiments has been shown to specifically perturb dynamin I-syndapin binding but not to interfere with interaction between dynamin I and other proteins (i.e., amphiphysin and endophilin) (Anggono et al., 2006). This limits the possibility that the functional effects are due to other dynamin binding partners. It has further been shown that syndapin links dynamin to N-WASP, an activator of the Arp2/3 complex, via heterologous oligomerization (Qualmann et al., 1999; Kessels and Qualmann, 2004, 2006). $\mathrm{N}$-WASP exists in an auto-inhibitory conformation in the resting state (Fawcett and Pawson, 2000; Kim et al., 2000; Prehoda et al., 2000). Upon binding to syndapin, N-WASP undergoes a conformational change to an active state (Dharmalingam et al., 2009). Previous studies have shown that syndapin regulates synaptic transmission by activating N-WASP (Kessels and Qualmann, 2002). We further show that N-WASP activity is required for fusion pore expansion. Blocking N-WASP activation by wiskostatin reduced catecholamine quantal size under enhanced stimulation suggesting that the drug prevented pore expansion.

Potential downstream events to N-WASP activation have been identified in the literature. In response to syndapin binding, $\mathrm{N}$-WASP has been shown to, in turn, activate the Arp2/3 complex, leading to localized actin polymerization (Dharmalingam et al., 2009). Moreover, work from the Bader group has demonstrated that N-WASP, the Arp2/3 complex, and F-actin accumulate at sites of exo-endocytosis (Gasman et al., 2004). Likewise, syndapin has been proposed to regulate endocytosis via a dynamin-mediated focal F-actin re-arrangement (Kessels and Qualmann, 2004). Thus, dynamin may regulate fusion pore expansion by recruitment of syndapin-N-WASP-Arp $2 / 3$ complex to the exo-endocytic site where they nucleate and/or organize F-actin fibers. Spatial actin polymerization may act coordinately with the motor protein myosin II to facilitate pore expansion. Indeed, recent studies conducted in chromaffin cells have demonstrated a role for myosin II in controlling fusion pore expansion and transmitter secretion (Neco et al., 2008; Berberian et al., 2009; Doreian et al., 2009). Thus, myosin II motor action may directly pull on F-actin fibers. This would provide force to either compress the granule toward the cell surface or pull the pore open, with either one driving the granule to collapse into the membrane. The relative roles for dynamin, N-WASP, actin rearrangement and myosin II motor activity will require detailed study but offer a testable mechanism for activity-dependent granule collapse.

\section{References}

Albillos A, Dernick G, Horstmann H, Almers W, Alvarez de Toledo G, Lindau M (1997) The exocytotic event in chromaffin cells revealed by patch amperometry. Nature 389:509-512.

Anantharam A, Bittner MA, Aikman RL, Stuenkel EL, Schmid SL, Axelrod D, Holz RW (2011) A new role for the dynamin GTPase in the regulation of fusion pore expansion. Mol Biol Cell 22:1907-1918.

Anggono V, Smillie KJ, Graham ME, Valova VA, Cousin MA, Robinson P) (2006) Syndapin I is the phosphorylation-regulated dynamin I partner in synaptic vesicle endocytosis. Nat Neurosci 9:752-760.

Barclay JW, Aldea M, Craig TJ, Morgan A, Burgoyne RD (2004) Regulation of the fusion pore conductance during exocytosis by cyclin-dependent kinase 5. J Biol Chem 279:41495-41503.

Bashkirov PV, Akimov SA, Evseev AI, Schmid SL, Zimmerberg J, Frolov VA (2008) GTPase cycle of dynamin is coupled to membrane squeeze and release, leading to spontaneous fission. Cell 135:1276-1286.

Berberian K, Torres AJ, Fang Q, Kisler K, Lindau M (2009) F-actin and myosin II accelerate catecholamine release from chromaffin granules. J Neurosci 29:863-870.

Brandt BL, Hagiwara S, Kidokoro Y, Miyazaki S (1976) Action potentials in the rat chromaffin cell and effects of acetylcholine. J Physiol 263:417-439.

Burgoyne RD (1995) Fast exocytosis and endocytosis triggered by depolarisation in single adrenal chromaffin cells before rapid Ca2 + current rundown. Pflugers Arch 430:213-219.

Chan SA, Smith C (2001) Physiological stimuli evoke two forms of endocytosis in bovine chromaffin cells. J Physiol 537:871-885 
Chan SA, Chow R, Smith C (2003) Calcium dependence of action potentialinduced endocytosis in chromaffin cells. Pflugers Arch 445:540-546.

Chen XK, Wang LC, Zhou Y, Cai Q, Prakriya M, Duan KL, Sheng ZH, Lingle C, Zhou Z (2005) Activation of GPCRs modulates quantal size in chromaffin cells through G(betagamma) and PKC. Nat Neurosci 8:11601168.

Chow RH, von Rüden L, Neher E (1992) Delay in vesicle fusion revealed by electrochemical monitoring of single secretory events in adrenal chromaffin cells. Nature 356:60-63.

Clayton EL, Anggono V, Smillie KJ, Chau N, Robinson PJ, Cousin MA (2009) The phospho-dependent dynamin-syndapin interaction triggers activity-dependent bulk endocytosis of synaptic vesicles. J Neurosci 29:7706-7717.

Crivellato E, Nico B, Ribatti D (2008) The chromaffin vesicle: advances in understanding the composition of a versatile, multifunctional secretory organelle. Anat Rec (Hoboken) 291:1587-1602.

Damke H, Baba T, Warnock DE, Schmid SL (1994) Induction of mutant dynamin specifically blocks endocytic coated vesicle formation. J Cell Biol 127:915-934.

Deacon SW, Peterson JR (2008) Chemical inhibition through conformational stabilization of Rho GTPase effectors. Handb Exp Pharmacol 186:431-460.

Dharmalingam E, Haeckel A, Pinyol R, Schwintzer L, Koch D, Kessels MM, Qualmann B (2009) F-BAR proteins of the syndapin family shape the plasma membrane and are crucial for neuromorphogenesis. J Neurosci 29:13315-13327.

Doreian BW, Fulop TG, Meklemburg RL, Smith CB (2009) Cortical F-actin, the exocytic mode, and neuropeptide release in mouse chromaffin cells is regulated by myristoylated alanine-rich C-kinase substrate and myosin II. Mol Biol Cell 20:3142-3154.

Elhamdani A, Palfrey HC, Artalejo CR (2001) Quantal size is dependent on stimulation frequency and calcium entry in calf chromaffin cells. Neuron 31:819-830.

Elhamdani A, Azizi F, Artalejo CR (2006) Double patch clamp reveals that transient fusion (kiss-and-run) is a major mechanism of secretion in calf adrenal chromaffin cells: high calcium shifts the mechanism from kissand-run to complete fusion. J Neurosci 26:3030-3036.

Engisch KL, Nowycky MC (1998) Compensatory and excess retrieval: two types of endocytosis following single step depolarizations in bovine adrenal chromaffin cells. J Physiol 506:591-608.

Fang Q, Berberian K, Gong LW, Hafez I, Sørensen JB, Lindau M (2008) The role of the $\mathrm{C}$ terminus of the SNARE protein SNAP-25 in fusion pore opening and a model for fusion pore mechanics. Proc Natl Acad Sci U S A 105:15388-15392.

Fawcett J, Pawson T (2000) Signal transduction. N-WASP regulation-the sting in the tail. Science 290:725-726.

Fulop T, Smith C (2006) Physiological stimulation regulates the exocytic mode through calcium activation of protein kinase $\mathrm{C}$ in mouse chromaffin cells. Biochem J 399:111-119.

Fulop T, Smith C (2007) Matching native electrical stimulation by graded chemical stimulation in isolated mouse adrenal chromaffin cells. J Neurosci Methods 166:195-202.

Fulop T, Radabaugh S, Smith C (2005) Activity-dependent differential transmitter release in mouse adrenal chromaffin cells. J Neurosci 25:7324-7332.

Fulop T, Doreian B, Smith C (2008) Dynamin I plays dual roles in the activity-dependent shift in exocytic mode in mouse adrenal chromaffin cells. Arch Biochem Biophys 477:146-154.

Gasman S, Chasserot-Golaz S, Malacombe M, Way M, Bader MF (2004) Regulated exocytosis in neuroendocrine cells: a role for subplasmalemmal Cdc42/N-WASP-induced actin filaments. Mol Biol Cell 15:520-531.

Gomez JF, Brioso MA, Machado JD, Sanchez JL, Borges R (2002) New approaches for analysis of amperometrical recordings. Ann N Y Acad Sci 971:647-654.

González-Jamett AM, Báez-Matus X, Hevia MA, Guerra MJ, Olivares MJ, Martínez AD, Neely A, Cárdenas AM (2010) The association of dynamin with synaptophysin regulates quantal size and duration of exocytotic events in chromaffin cells. J Neurosci 30:10683-10691.

Graham ME, O'Callaghan DW, McMahon HT, Burgoyne RD (2002) Dynamin-dependent and dynamin-independent processes contribute to the regulation of single vesicle release kinetics and quantal size. Proc Natl Acad Sci U S A 99:7124-7129.
Habib KE, Gold PW, Chrousos GP (2001) Neuroendocrinology of stress. Endocrinol Metab Clin North Am 30:695-728; vii-viii.

Kessels MM, Qualmann B (2002) Syndapins integrate N-WASP in receptormediated endocytosis. EMBO J 21:6083-6094.

Kessels MM, Qualmann B (2004) The syndapin protein family: linking membrane trafficking with the cytoskeleton. J Cell Sci 117:3077-3086.

Kessels MM, Qualmann B (2006) Syndapin oligomers interconnect the machineries for endocytic vesicle formation and actin polymerization. J Biol Chem 281:13285-13299.

Kim AS, Kakalis LT, Abdul-Manan N, Liu GA, Rosen MK (2000) Autoinhibition and activation mechanisms of the Wiskott-Aldrich syndrome protein. Nature 404:151-158.

Klingauf J, Neher E (1997) Modeling buffered Ca2+ diffusion near the membrane: implications for secretion in neuroendocrine cells. Biophys J 72:674-690.

Lai MM, Hong JJ, Ruggiero AM, Burnett PE, Slepnev VI, De Camilli P, Snyder SH (1999) The calcineurin-dynamin 1 complex as a calcium sensor for synaptic vesicle endocytosis. J Biol Chem 274:25963-25966.

Leszczyszyn DJ, Jankowski JA, Viveros OH, Diliberto EJ Jr, Near JA, Wightman RM (1990) Nicotinic receptor-mediated catecholamine secretion from individual chromaffin cells. Chemical evidence for exocytosis. J Biol Chem 265:14736-14737.

Lindau M, Alvarez de Toledo G (2003) The fusion pore. Biochim Biophys Acta 1641:167-173.

Liu JP, Sim AT, Robinson PJ (1994) Calcineurin inhibition of dynamin I GTPase activity coupled to nerve terminal depolarization. Science 265:970-973.

Mosharov EV, Sulzer D (2005) Analysis of exocytotic events recorded by amperometry. Nat Methods 2:651-658.

Neco P, Fernández-Peruchena C, Navas S, Gutiérrez LM, de Toledo GA, Alés E (2008) Myosin II contributes to fusion pore expansion during exocytosis. J Biol Chem 283:10949-10957.

Ngatchou AN, Kisler K, Fang Q, Walter AM, Zhao Y, Bruns D, Sørensen JB, Lindau M (2010) Role of the synaptobrevin C terminus in fusion pore formation. Proc Natl Acad Sci U S A 107:18463-18468.

Nguyen C, Bibb JA (2003) Cdk5 and the mystery of synaptic vesicle endocytosis. J Cell Biol 163:697-699.

Pérez-Alvarez A, Hernández-Vivanco A, Albillos A (2010) Past, present and future of human chromaffin cells: role in physiology and therapeutics. Cell Mol Neurobiol 30:1407-1415.

Perrais D, Kleppe IC, Taraska JW, Almers W (2004) Recapture after exocytosis causes differential retention of protein in granules of bovine chromaffin cells. J Physiol 560:413-428.

Perrino BA, Ng LY, Soderling TR (1995) Calcium regulation of calcineurin phosphatase activity by its B subunit and calmodulin. Role of the autoinhibitory domain. J Biol Chem 270:340-346.

Peterson JR, Bickford LC, Morgan D, Kim AS, Ouerfelli O, Kirschner MW, Rosen MK (2004) Chemical inhibition of N-WASP by stabilization of a native autoinhibited conformation. Nat Struct Mol Biol 11:747-755.

Prehoda KE, Scott JA, Mullins RD, Lim WA (2000) Integration of multiple signals through cooperative regulation of the N-WASP-Arp2/3 complex. Science 290:801-806.

Qualmann B, Roos J, DiGregorio PJ, Kelly RB (1999) Syndapin I, a synaptic dynamin-binding protein that associates with the neural Wiskott-Aldrich syndrome protein. Mol Biol Cell 10:501-513.

Rahamimoff R, Fernandez JM (1997) Pre- and postfusion regulation of transmitter release. Neuron 18:17-27.

Ramachandran R (2011) Vesicle scission: dynamin. Semin Cell Dev Biol 22:10-17.

Ryan TA (2003) Kiss-and-run, fuse-pinch-and-linger, fuse-and-collapse: the life and times of a neurosecretory granule. Proc Natl Acad Sci U S A 100:2171-2173.

Schmid SL, Frolov VA (2011) Dynamin: functional design of a membrane fission catalyst. Annu Rev Cell Dev Biol 27:79-105.

Smith C, Neher E (1997) Multiple forms of endocytosis in bovine adrenal chromaffin cells. J Cell Biol 139:885-894.

Stewart AA, Ingebritsen TS, Cohen P (1983) The protein phosphatases involved in cellular regulation. 5. Purification and properties of a $\mathrm{Ca} 2+/$ calmodulin-dependent protein phosphatase (2B) from rabbit skeletal muscle. Eur J Biochem 132:289-295.

Terada H, Matsushita M, Lu YF, Shirai T, Li ST, Tomizawa K, Moriwaki A, Nishio S, Date I, Ohmoto T, Matsui H (2003) Inhibition of excitatory 
neuronal cell death by cell-permeable calcineurin autoinhibitory peptide. J Neurochem 87:1145-1151.

Vollmer RR, Balcita JJ, Sved AF, Edwards DJ (1997) Adrenal epinephrine and norepinephrine release to hypoglycemia measured by microdialysis in conscious rats. Am J Physiol 273:R1758-1763.

Wang CT, Bai J, Chang PY, Chapman ER, Jackson MB (2006) Synaptotagmin$\mathrm{Ca} 2+$ triggers two sequential steps in regulated exocytosis in rat PC12 cells: fusion pore opening and fusion pore dilation. J Physiol 570:295-307.

Wiederhold K, Kloepper TH, Walter AM, Stein A, Kienle N, Sørensen JB, Fasshauer D (2010) A coiled coil trigger site is essential for rapid binding of synaptobrevin to the SNARE acceptor complex. J Biol Chem 285:21549-21559.

Wightman RM, Jankowski JA, Kennedy RT, Kawagoe KT, Schroeder TJ,
Leszczyszyn DJ, Near JA, Diliberto EJ Jr, Viveros OH (1991) Temporally resolved catecholamine spikes correspond to single vesicle release from individual chromaffin cells. Proc Natl Acad Sci USA 88:10754-10758

Winkler H, Westhead E (1980) The molecular organization of adrenal chromaffin granules. Neuroscience 5:1803-1823.

Xue J, Graham ME, Novelle AE, Sue N, Gray N, McNiven MA, Smillie KJ, Cousin MA, Robinson PJ (2011) Calcineurin selectively docks with the dynamin Ixb splice variant to regulate activity-dependent bulk endocytosis. J Biol Chem 286:30295-30303.

Zhang Z, Hui E, Chapman ER, Jackson MB (2010) Regulation of exocytosis and fusion pores by synaptotagmin-effector interactions. Mol Biol Cell 21:2821-2831. 